\title{
Erratum
}

\section{Radiation-induced torques on spheroids}

\author{
S. Breiter ${ }^{1}$, H. Michalska ${ }^{1}$, D. Vokrouhlický ${ }^{2}$, and W. Borczyk ${ }^{1}$ \\ 1 Astronomical Observatory, A. Mickiewicz University, Sloneczna 36, 60-286 Poznan, Poland \\ e-mail: breiter@amu.edu.pl \\ 2 Institute of Astronomy, Charles University, V Holešovickách 2, 18000 Prague, Czech Republic \\ e-mail: vokrouhl@mbox.cesnet.cz
}

A\&A 471, 345-353 (2007), DOI: 10.1051/0004-6361:20077313

Key words. errata, addenda - methods: analytical - celestial mechanics - minor planets, asteroids

Our paper discussing the YORP torques on ellipsoids of revolution (Breiter et al. 2007) contains three incorrectly typeset equations: (79) and (106) have wrong signs, whereas (105) has a wrong factor 2 instead of $\frac{1}{2}$. The correct form of the equations is

$v_{2}=-\frac{1}{12}\left(9-5 x_{\odot}^{2}\right)$,

$\left\langle T_{\perp}\right\rangle=-\frac{1}{2} \alpha^{\prime} \sin \varepsilon \cos \varepsilon \sin \delta \sum_{j \geq 1} \mathrm{e}^{2 j} c_{j}$,

$c_{2}=-\frac{1}{64}\left(28+15 \sin ^{2} \varepsilon\right)$.
In a recent paper (Breiter \& Michalska 2008) we also show how to convert the results obtained by means of the simplistic "delayed Sun" approach to a more realistic thermal lag model.

\section{References}

Breiter, S., Michalska, H., Vokrouhlický, D., \& Borczyk, W. 2007, A\&A, 471, 345

Breiter, S., \& Michalska, H. 2008, MNRAS, submitted 